\title{
THE PRESENT CONDITION OF SCIENCE IN THE HIGH SCHOOL.
}

\author{
By ADA L. WECKEL, \\ Oak Park High School, Oak Park, Ill.
}

A new problem is at hand. How can it be solved? If it be open to experimentation, our usual scientific mode of attack is to set up suitable apparatus, perform experiments, record data and results, and from these, if possible, draw conclusions.

A probiem which I have wanted answered for some time is this: What is the present condition of science in the high school? Can this be answered experimentally? I think it can. The apparatus has been set up, taken apart and reconstructed; the experiment has been in progress for many years, and results, though constantly changing, have been obtained, though few of these results have been recorded and few data are accessible.

Are not the conditions of scientific training in our secondary schools worthy of scientific analysis? Can we give them the proper consideration unless we have some data at hand? It would appear that we have relied long enough on general impressious and claims.

Be this as it may, I will record some data which I have recently collected-the present results of this experiment. Present, I say, for no doubt to-morrow they may change. But do we disregard temporary results in our experiments in the laboratory? Usually not, and frequently such results determine cur methods for further experimentation. Why cannot our present results in this great problem of science help to make our future ones more definite? Certainly this has not been true in the past, for a subject could scarcely be in a more chaotic condition than is science in the high school at present. 'This, however, only helps to make the problem more interesting and the more worthy of out earnest and coördinated consideration.

Some time ago I sent the following questions to fifty of the larger high schools, principally in the Middle West.

1. Name of bigh school.

2. How many years of science are required for graduation in your high school?

3. What are the sciences required?

4. For how many years of science will credit toward graduation be given?

5. Which of the following sciences are taught in your high school, and in which years may they be elected? 
Astronomy

Biology

Botany

Chemistry
Physical Geography

Physiology

Physics

Zö̈logy.

A summary follows of the data received from forty-eight ligh schools in reply to these questions.

I. Amount of science required.

Schools not requiring science in all courses, 35 per cent.

Schools requiring one sear of science in all courses, 46 per cent.

Schools requiring two years of science in all courses, 19 per cent.

Schools requiring at least one year of science, 65 per cent.

2. Of schools which require one year of science:

$36 \%$ requile physics.

$32 \%$ permit a choice of any science.

14\% require physics or chemistry.

$9 \%$ require physiology and physical geography.

$4 \%$ require physical geography.

$4 \%$ require physical geography, botany, or physics.

Of schools which require two years of science:

$44 \%$ require physics.

$33 \%$ require physics or chemistry.

$33 \%$ require botany or zoölogy.

$22 \%$ permit a choice of any science, for one of two years.

$11 \%$ require chemistry.

$11 \%$ require biology.

$11 \%$ require commercial and physical geography.

$11 \%$ require botany and physiology. .

3. Providing other requirements are met, the maximum number of years of science for which credit toward graduation will be given is as follows:

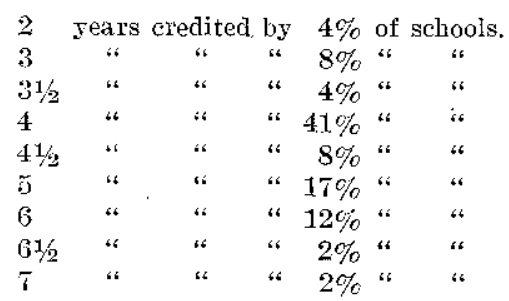

4. The year in which any particular science may be elected is shown by the following table. These data represent 37 schools. Whenever in physics or chemistry a choice is given as between third and fourth years the subject is tabulated as belonging to the third year. The numbers represent percentage of the whole number of schools allowing election of the given subject in the year indicated. 


\begin{tabular}{|c|c|c|c|c|c|c|c|c|c|}
\hline Year & $\begin{array}{l}\overline{\mathrm{g}} \\
\text { 产 } \\
\end{array}$ & 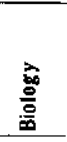 & 害 & 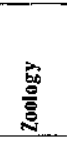 & 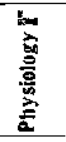 & 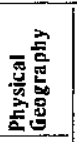 & 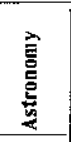 & 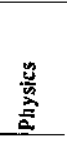 & 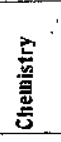 \\
\hline 1st year & & $33 \%$ & $43 \%$ & $13 \%$ & $46 \%$ & $62 \%$ & $0 \%$ & $0 \%$ & $0 \%$ \\
\hline 2nd year & & 55 & 40 & 63 & 26 & 20 & 0 & 5 & 0 \\
\hline 3rd year & & 0 & 9 & 13 & 11 & 5 & 25 & 50 & 68 \\
\hline 4 th year & & 0 & 3 & 0 & 7 & 5 & 64 & 42 & 29 \\
\hline any year & & .11 & 3 & 5 & 7 & 5 & 12 & 3 & 2 \\
\hline
\end{tabular}

It will be noted from the above that there is the following distribution of preferences for particular years:

Physical Geography is given in the first year by $62 \%$ of schools.

Physiology is given in the first year by $46 \%$ of schools.

Botany is given in the first year by $43 \%$ of schools.

Zoölogy is given in the second year by $63 \%$ of schools.

Biology is given in the second year by $55 \%$ of schools.

Chemistry is given in the third year by $68 \%$ of schools.

Physics is given in the third year by $50 \%$ of schools.

Astronomy is given in the fourth year by $64 \%$ of schools.

These results, although very indefinite, suggest many interesting problems:

First, are we educating our children so as to fit them best for the period in which they are living? Few persons would disfute the fact that we are living in a scientific period, yet thirtyfive per cent of our larger high schools do not require so much as one year of science of all pupils! This means that a large percentage of children receive no scientific training.

Second, it is apparent that in most high schools there is not a definite sequence of sciences. Science is not considered as a whole, but as a series of units. This often causes repetition, and perhaps sometimes gaps in the work. Text-books cannot be written so that they are suitable for use in any year in the high school, preceded by any or no science. Geometries are not written so that they may at will precede or follow high school algebra. Is it not possible to remedy this evil in science? Are not some of us willing to adapt our subject to the first or second year, rather than the third or fourth where we all think our specialty belongs!

Third, which shall be the required science? This will be 
largely determined when the sequence of sciences is determined.

These and other similar existing conditions indicate, it seems to me, the fact that science teachers should be attempting to place the sciences in high schools upon a scientific basis. The amount of required science, the sequence of sciences, the science or sciences required, the sciences offered, etc., ought not to be a mere matter of chance or expediency as is so often the case at present; these things ought to be based upon accurate knowledge.

\section{THE HIGH SCHOOL SCIENCE SITUATION.}

\section{By W. L. EIKENBERRY, University High School, University of Chicago.}

lif it is true that periods of vigorous discussion are also likely to be periods of advance as well, we may hope to see early and definite results leading toward the solution of some of the problems of high school science. The variety of information developed in the present discussion is surprising. We have been told that there is among pupils a widespread distaste for science and that there is not; that the elections of sciences are increasing and that they are decreasing; that a certain subject will fail because the teachers are not prepared to teach it, while in another subject all the reported failures are due to the same cause and the subject will therefore ultimately succeed; that all the various sciences are but departments of one fundamental and all-embracing science, though as to which one shall lead there is an unfortunate difference of opinion. Different writers have different candidates for first place and singularly enough, in each case it seems to the science to which the writer has given closest study. Geography, physics, biology, and physiology are all candidates for the rrost prominent place on the ticket, and agriculture, domestic science, and chemistry are circulating petitions.

To an outsider there must appear great probability that we shall finally rediscover the fact that the divisions of the field of science are so poorly fenced off from each other that there is little difficulty in passing to any part of the field, regardless of the starting point.

The almost entire absence from the discussion of any tangible data bearing upon the questions at issue makes it hazardous to draw conclusions, but one may at least venture to suggest that 